\title{
La construcción de las identidades lingüísticas: el caso de la variedad andaluza del español y las modalidades meridionales del serbio
}

Palabras clave: la identidad lingüística, el andaluz, variedades meridionales del serbio, prestigio lingüístico, estigmatización.

\section{Introducción}

El artículo ofrece una visión general a la identidad lingüística de los hablantes de la variedad andaluza del español y las hablas regionales del sur de Serbia. Se interpretan tanto los conceptos de identidad e identidad lingüística, como la relación entre la estandarización de las lenguas y la ideología lingüística. Se explica la posición de dichas hablas con relación a la lengua estándar, las actitudes negativas que comparten y las razones del desprestigio que las acompañan. Asimismo se aclaran los rasgos sociolingüísticos, los asuntos de discriminación y estigmatización de los hablantes de las variedades menos aceptadas o rechazadas por la sociedad. A través de la comparación de los fenómenos lingüísticos se confronta la cuestión de la identidad lingüística de los hablantes de ambas lenguas y se contrastan las actitudes de los hablantes de las dos variedades.

La base teórica de la investigación es la sociolingüística crítica que analiza las relaciones de desigualdad entre los diferentes grupos sociales causados por varios motivos: clase social, edad, género, etnicidad, etc. Explicando los aspectos sociales de la práctica lingüística, la sociolingüística crítica intenta, si no extinguir, al menos reducir los prejuicios, los estereotipos, las diferencias y desigualdades sociales (Filipović, 2009: 8). 
Dado que se trata de dos lenguas diversificadas, fragmentadas y policéntricas, el objetivo es demostrar que no hay variedades superiores a las demás en un sentido lingüístico; en cuanto al prestigio social, sí existen las variedades que gozan de menor prestigio y escasa estimación sociocultural (Narbona, 2009b: 28, 33; Kordić, 2010: 96, 295). Es cierto que algunas variedades tienen prioridad sobre otras y se consideran la mejor forma de la lengua, y lo que las hace más prominentes son los modelos culturales elegidos por los grupos más poderosos dentro de la sociedad. El poder social e ideologías lingüísticas generales y/o actuales dictan la norma según la cual los miembros de una comunidad deben usar la variedad dominante y la más prestigiosa. El supuesto preliminar es que las ideologías lingüísticas junto con las circunstancias sociales, económicas y políticas han producido la estigmatización de la variedad andaluza y las hablas meridionales del serbio, creando así los estereotipos acerca de ellos. Otro objetivo sería comprobar que la identidad lingüística es una de las componentes más importantes de la identidad personal y sociocultural. Se ha hecho una investigación a propósito de este artículo entre los estudiantes de filología hispánica de la Universidad de Belgradoํ. La encuesta anónima incluye una serie de preguntas sobre la discriminación y estigmatización de las hablas subestándar del sur de Serbia y España, con las cuales se comprueba el nivel de aceptación de dichas variedades. Además, se han verificado las actitudes de los hablantes del serbio hacia la importancia de la lengua en la creación de la propia identidad.

1 La encuesta cuenta con 16 nociones que se valoran de 1 a 5 (la escala de Likert), donde 1 significa nada de acuerdo y 5 totalmente de acuerdo. Con la puntuación de cada noción se obtiene la suma total que expresa la opinión, positiva o negativa, de los interrogados.

Los estudiantes fueron divididos en dos grupos: $\mathbf{1}^{\mathbf{0}}$ grupo (los 38 estudiantes del primer año de estudio) y $\mathbf{2}^{\circ}$ grupo (los 41 estudiantes del cuarto y último año de estudios académicos). La razón es comprobar la influencia de la educación formal lingüística y el posible cambio de las actitudes hacia el uso de la lengua no estándar durante la carrera académica. Ambos grupos son bastante heterogéneos, porque los estudiantes provienen de todas partes del país.

Con la encuesta se han averiguado las actitudes de los serbiohablantes hacia las variedades serbias, así como las españolas. Dicha investigación es parte de un estudio más grande en la que se comprobarán igualmente las actitudes de los hablantes del español. En este momento, el análisis incluirá sólo los resultados obtenidos por otros autores en cuanto a la opinión de los hispanohablantes.

Dado que se trata del inicio de una investigación más amplia que forma parte de la tesis doctoral, los numerosos datos están parcialmente procesados. Debido a la longitud requerida de este artículo, no se proporciona un análisis detallado y la comparación de todas las respuestas obtenidas. 


\section{El concepto de la identidad}

La identidad es un término de significado múltiple, muy común hoy en día. Se encuentra en todos contextos: en los trabajos de investigación en el campo de las humanidades y ciencias sociales, en los medios de comunicación, en los debates políticos, conflictos de varios tipos, llegando a ser una palabra universal de moda de nuestro tiempo (Bugarski, 2010: 11, 12).

La identidad es lo que somos, la continuidad de propiedades esenciales que nos definen. Es la imagen de uno mismo, un conjunto de representaciones mentales, valoraciones e ideas que uno forma sobre su propio yo. Esta imagen está directamente relacionada con las nociones de autoestima e individualización, porque indica todas las diferencias personales que nos destacan y distinguen de otras personas (Vučina/Filipović, 2009: 29, 30). No es algo innato, sino se construye a lo largo de la vida de un individuo y está siempre compuesta por una serie de componentes. La identidad personal o individual implica las diferencias personales que nos difieren de otros y nos caracterizan como individuos únicos. El concepto de la identidad social o cultural determina las personas en entorno social, cultural e histórico. Justo en este nivel, la identidad se convierte en un poderoso argumento tanto de enfrentamientos con los grupos provenientes de diferentes contextos sociales, como de asociación con las diferentes agrupaciones sociales, culturales y políticas (Filipović, 2009: 21). La identidad social es una noción compleja, una categoría personal y colectiva. Ninguna sociedad tiene un sistema de conocimiento colectivo uniforme y homogéneo, sino depende de varios y variables factores que contribuyen al desarrollo de los individuos y formación de la identidad social (Filipović, 2009: 21, 22).

Bugarski afirma que la identidad tiene numerosos "estratos": nacional, religioso, cultural, lingual, generacional, de género, político, y especifica tres "grados" de la identidad: fuerte, medio y débil.

Distingue tres "niveles" de identidad:

1. La identidad como bumanidad (el nivel biológico de la identidad - la lengua humana);

2. La identidad como colectividad (el nivel sociológico de la identidad - una lengua en particular o una variedad);

3. La identidad como individualidad (el nivel psicológico de la identidad - el idiolecto). 
Los niveles 2 y 3 están estrechamente relacionados y dependientes entre sí. Están cruzados con dichos estratos y grados, formando así una estructura compleja y ramificada, constituida de elementos socialmente definidos y sujetos a cambios (Bugarski, 2010: 13, 14).

\section{La identidad lingüística}

Además de ser un "vehículo" de interacción, la lengua es también un factor de identidad a través del cual se establecen los lazos con otras personas. Es el símbolo de pertenencia a un colectivo y distanciamiento de otros (Amorós, 2014: 19, 21).

Desde el siglo XVIII la lengua ocupa un sitio superior y tiene una posición de honor entre otros componentes de la identidad. La legua se consideraba como un arma poderosa en la lucha por los valores nacionales y la seña de cohesión e identidad nacional. De aquí proviene la "trinidad" de lengua, nación y estado que supone que un pueblo no puede sobrevivir sin su propia lengua y su propio estado (Bugarski, 2010: 19-21). Bugarski defiende el argumento de que la identidad lingüística no se considera el fundamento de la identidad, sino uno de varios elementos que la componen. Sin embargo, algunos autores que problematizan este tema opinan lo contrario y consideran la lengua un elemento de suma importancia de la identidad de una persona. Tabouret (1997: 317) expone que la identidad individual y la identidad social están mediadas por el idioma, siendo el idioma el enlace que une la identidad individual y social. El papel y la importancia de la lengua son variables con respecto a la identidad absoluta de una persona. Los factores sociopolíticos y culturales en gran medida determinan la sustancialidad de la identidad lingüística (Vučina/ Filipović, 2009: 36).

Kordić asocia la identidad lingüística y la identidad nacional comentando la tesis muy conocida entre los eslavos del sur de que la "identidad nacional depende de la lengua". La autora niega la tesis señalando como ejemplo la nación austríaca para cual la cuestión de la identidad tiene poco que ver con la lengua porque hay muchas naciones que no tienen su propia lengua (Kordić, 2010: 177,180 ). Por otra parte, una lengua puede relacionarse con varias y diversas identidades, siendo el inglés un ejemplo paradigmático (Amorós, 2014: 20).

Jaspal/Sitaridou (2013) investigan el fenómeno del impacto de la estigmatización lingüística para el funcionamiento de identidad en el ejemplo del andaluz y analizan las posibles estrategias para enfrentar las amenazas a la identidad. 
El uso de la variedad menos apreciada por la sociedad puede provocar consecuencias negativas para sus hablantes, de modo de que la estigma social puede afectar el comportamiento lingüístico de los hablantes y despertar la conciencia de inferioridad (Jaspal/Sitaridou, 2013: 96-97).

Las respuestas a las preguntas de la encuesta que se refieren a la identidad lingüística manifiestan que la mayoría de los examinados muestra un gran acuerdo con el juicio La identidad lingüística es un elemento muy importante de la identidad personal: el $1^{\circ}$ grupo lo evaluó con 4,18 , mientras que el $2^{\circ}$ grupo lo evaluó con 4,05. En cuanto a la importancia de la lengua estándar en la conservación de la identidad nacional, el $1^{\circ}$ grupo lo cualificó con 3,18 , y el $2^{\circ}$ grupo con 2,9 .

\section{$4 \quad$ Las características de la variedad andaluza y las hablas meridionales del serbio, y su posición dentro de la lengua estándar}

El andaluz o la variedad (la modalidad, el habla) andaluza, como la vamos a denominar a lo largo de este trabajo ${ }^{2}$, es -sin duda alguna- la más investigada y mejor descrita de todas las hablas del español. El estudio riguroso empezó a finales de la década de 1950 con un análisis de testimonios escritos y documentos históricos (Cano, 2001: 33). Así comenzaron a publicarse los trabajos científicos con los que se ha formado una idea sobre el estado actual, los juicios y valoraciones sobre las formas de hablar en Andalucía. Estudios recientes han contribuido a la clarificación y difusión de los conocimientos sobre el andaluz.

La variedad andaluza se caracteriza por una extrema heterogeneidad. Existe un continuo atravesado por isoglosas geolingüísticas y sociales, pero no se pueden determinar los límites ni forma unitaria de la modalidad regional. Por razones históricas, socioculturales y sociolingüísticas, esta variedad se puede dividir en dos partes de habla dentro de una misma comunidad lingüística: la oriental y la occidental (Villena, 2006: 233, 234).

2 Conviene usar los términos variedad (modalidad) lingüistica y el babla que el dialecto, siendo más "neutrales" con respecto al mérito y estimación de las diferencias lingüísticas. Dentro de la dialectología tradicional, el dialecto se define como un sistema variable, inestable, no estandarizado, vernáculo, del bajo aprecio y un estatus subordinado en comparación con la variedad estándar. Para impedir la argumentación basada en los juicios de valor y los criterios extralingüísticos, sería mejor emplear el término variedad, "desprovisto de connotaciones ideológicas" (Amorós, 2014: 21). La variedad representa cualquier sistema lingüístico usado por los hablantes como lengua materna, a pesar de su posición social y normativa, poder político y testimonios escritos (Filipović, 2009: 13, 14). 
Por otra parte, las hablas meridionales del serbio no están exploradas detalladamente. La mayoría de los estudios dedicados al tema ha tratado sus características gramaticales, mientras que las actitudes hacia estas variedades no han sido tan investigadas. Con la descomposición política de Yugoslavia, se ha modificado la imagen dialectológica del serbo-croata (croata-serbio), y las comunidades lingüísticas respectivas igualmente sufrieron graves cambios. Por consiguiente, la identidad de los hablantes igualmente sufrió transformaciones importantes. Así las diferencias entre los dialectos del serbio de hoy pueden ser más grandes que las de ciertos dialectos de la comunidad lingüística de la ex-Yugoslavia (Ivić, 2009: 5-6).

La variedad de la ciudad de Niš y sus alrededores pertenece al continuo dialectal denominado como prizrensko-timočki que adjunta un territorio grande del sureste de Serbia. Estas variedades de la Serbia meridional y oriental son justamente las que difieren más en comparación con el resto de hablas del serbio (Ivić, 2009: 10). Las diferencias han provocado actitudes negativas creencias en cuanto a su prestigio lingüístico.

Las variedades meridionales del serbio se consideran innovadoras por la desaparición de la cantidad prosódica, la declinación y comparación analíticas, la pérdida del infinitivo, y el uso de formas duales de los pronombres personales (Ivić, 2001: 146, 147). Estos rasgos son más importantes en el nivel estructural que los arcaísmos gramaticales, calificados antes como la característica decisiva para la división de dialectos serbios (Ivić, 2009: 11).

Los arcaísmos significativos de este grupo son las siguientes:

1. El mantenimiento de la $l$ silábica (la $l$ vocálica o la $l$ sonante);

2. El mantenimiento de la -r final de sílaba;

3. La acentuación antigua, donde el acento queda en la posición que tenía en la lengua pre-eslava tardía.

El sistema fonológico no muestra grandes diferencias en comparación con la variedad estándar. En la realización de los fonemas no se observan discrepancias significativas (Toma, 1998: 35 ).

En las características importantes se incluyen las nivelaciones o las faltas de oposición en las formas de ciertos casos:

1. La falta de oposición de nominativo de singular que termina en - $a$ con un

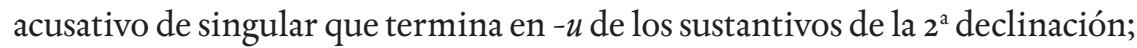

2. La falta de distinción entre el acusativo y locativo, y normalmente instrumental; 
3. El locativo de plural es igual al genitivo de plural;

4. El instrumental equivale al dativo (Ivić, 2009: 12-13, 153, 155).

Belić (1999: 67) afirma que la fonética de estos dialectos se caracteriza por los siguientes rasgos:

1. El mantenimiento de los sonidos antiguos;

2. La asimilación de los sonidos: la palatalización y la labialización;

3. La pérdida de la cantidad y cualidad acentual;

4. La influencia de la acentuación en el cambio de las vocales.

Es importante destacar el hecho de que no todas las hablas de este grupo conocen las características anteriormente citadas. Estos rasgos no se encuentran dentro del estánda, por lo cual las variedades mencionadas carecen de prestigio social.

Aquí enumeraré los rasgos fonéticos que en mayor o menor grado distinguen la variedad andaluza del resto de las hablas castellanas. La mayoría de las distinciones pertenece al campo de fonética, el nivel lingüístico sujeto al cambio más que los demás.

1. El seseo - la pronunciación de los fonemas $/ \theta / \mathrm{y} / \mathrm{s} / \mathrm{como} / \mathrm{s} /$;

2. El ceceo - la pronunciación de $/ \theta / \mathrm{y} / \mathrm{s} / \mathrm{como} / \theta / 3$;

3. El yeísmo - la igualación de $l l$ y $y$, o sea la igualación de los fonemas $/ \lambda / \mathrm{y} / \mathrm{y} /$;

4. La confusión entre $-r$ y $-l$ implosivas o finales de sílaba;

5. La pérdida de la $-d$ - intervocálica;

6. El debilitamiento de la $j$ castellana;

7. La pérdida de las consonantes finales;

8. La relajación, o sea la fricación de la $c b$;

9. La apertura y alargamiento de las vocales finales tras la eliminación de la $-s^{4}$; 10. La igualación de $-a(s)$ y $-e(s),-a ́(l)$ y $-e(l),-a ́(r)$ y $-e(r)$ (Cano, 2001: 44, 45);

11. La entonación más variada y ágil, el ritmo más rápido y vivaz (Narbona, 2009b: 33).

Hay que destacar que muchas de estas diferencias caracterizan otras variedades del español. El yeísmo, por ejemplo, predomina en las hablas castellanas peninsulares e hispanoamericanas, mientras que las variedades lleístas ocupan una extensión geográfica muy limitada. Los rasgos 5-8 tampoco pueden considerarse

3 Este complejo conjunto de realizaciones igualadoras se considera casi unánimemente más definidor del andaluz. La mayoría de las discusiones sobre los orígenes históricos del andaluz se ha planteado acerca de este fenómeno, "la confusión de los sonidos que acabarían originando las eses y cetas del español central y septentrional" (Cano, 2001: 37, 39)

4 Un fenómeno de extraordinaria vitalidad con gran capacidad expansiva y con escaso prestigio social (Bustos, 2001: 265). 
diferentes de otros territorios del habla española. Al contrario, los rasgos 9-11 sí son andaluces, teniendo en cuenta su difusión actual (Cano, 2001: 44, 45).

El español demuestra una tendencia universal hacia la sílaba abierta y los rasgos 6-8 y 11 claramente ilustran esta preferencia. Este fenómeno está presente en casi todas las modalidades del español y se puede denominar como una "ley fonológica del español" (Morillo, 2001: 67).

Asimismo, no todos los rasgos mencionados aquí marcan todas las variedades del "andaluz". Por ejemplo, la característica más notable de las hablas andaluzas - seseo/ceceo- no ocupa toda Andalucía, sino que al menos una tercera parte quedó desde siempre fuera de este proceso (Cano, 2001: 42).

Puede ser que el fenómeno de la aspiración de la -s final de sílaba y final de palabra sea el único que caracteriza a todos los hablantes de Andalucía y como tal, forma parte de su identidad lingüística.

Además, las características de la variedad andaluza se refieren casi únicamente a las actuaciones orales. En la lengua escrita no existen ningunas discrepancias, por lo cual la modalidad hablada ha atraído la mayor atención de los investigadores (Narbona, 2001: 19; Cano Aguilar, 2001: 45). Por orto lado, las diferencias entre la variedad meridional serbia y la estándar muestran las disidencias morfológicas y morfosintácticas que se caracterizan por una ortografía distinta. Por consiguiente, esta variedad es sumamente estigmatizada.

Lo que parece ser una característica exclusiva del andaluz frente al resto de las hablas españolas es la pronunciación del grupo consonántico -st- como una africada. Dado que el español generalmente demuestra una tendencia fuerte hacia la sílaba abierta, la -s de la coda silábica se debilita y la $t$ - del ataque de la sílaba siguiente representa el elemento oclusivo de la africada. La secuencia de dos sonidos es de larga duración, lo que también indica que se trata de un fonema africado. Sostengo que este rasgo es típico de los hablantes de la modalidad andaluza.

\begin{tabular}{|c|c|c|c|}
\hline la palabra & $\begin{array}{c}\text { pronunciación } \\
\text { enfática }\end{array}$ & aspiración de la -s- & $\begin{array}{c}\text { africatización del } \\
\text { grupo -st- }\end{array}$ \\
\hline esto & [ésto] & [éhto] & [étşo] \\
\hline visto & [vísto] & [víhto] & [vítşo] \\
\hline estudio & [estúdyo] & [ehtúdyo] & [etşúdyo] \\
\hline ministro & [minístro] & [miníhtro] & [minítşro] \\
\hline estoy & [estóy] & [ehtóy] & [etşóy] \\
\hline periodista & [peryodísta] & [peryodíhta] & [peryodítşa] \\
\hline
\end{tabular}


Según de Moya et al. (2007) es un efecto del complejo proceso de la aspiración, asimilación y pérdida de la -s implosiva. El grupo -st- se pronuncia como una africada [tş]: "Se trata de un sonido africado, que se articula en la zona dento-alveolar con la parte más adelantada del predorso de la lengua" (Moya et al, 2007: 276). El elemento fricativo [ş] es posterior a la oclusión dental [t], conservando el mismo punto de articulación pero no el modo. El sonido que suena al oído como una africada tiene los componentes "colocados en orden inverso: primero la fricación y en segundo lugar la oclusión" (Moya et al, 2007: 277). Se trata de un fenómeno reciente y en marcha, más habitual y frecuente entre los jóvenes, con escasa incidencia en la tercera generación. Al parecer, el fenómeno cuenta con un prestigio en ascenso (Moya et al, 2007: 281).

Otro asunto muy importante es la diferencia entre las hablas en zonas urbanas y las de los pueblos. Las diferencias pueden ser tan grandes que podríamos decir que existen dos tipos del habla andaluza: la modalidad urbana y la rural. Se trata de una variedad muy heterogénea, fragmentada por isoglosas dentro del marco ciudad/pueblo.

De las escasas diferencias morfosintácticas, que no están extendidas por toda Andalucía, subrayo las siguientes:

1. La diferencia más destacada es el uso del pronombre ustedes en vez de vosotros 5

2. Las interferencias en los usos de la, le y lo.

El vocabulario del andaluz es conservador y arcaizante a diferencia de los rasgos fonético-fonológicos innovadores. El léxico se caracteriza por arcaísmos reemplazados por otras palabras en el resto de España, muchos de los cuales son arabismos. La presencia del gran número de arcaísmos es de hecho la característica común de las dos modalidades. Las hablas meridionales del serbio abundan en los turcismos que no se usan en el serbio estándar.

Según Narbona, se considera que los andaluces son "graciosos y chistosos (...), por un lado, y que hablan mal el español (cuesta entenderlos), por otro" (2009a: 18). Lo mismo vale para los hablantes del serbio meridional. Les juzgan como interesantes y donosos, porque su manera de hablar provoca la simpatía, la risa, pero a veces la burla y el desprecio. Otros estereotipos y prejuicios predominantes: son divertidos y alegres, tienen buen sentido del

5 Este rasgo divide Andalucía en dos partes casi idénticas: en la parte occidental no se usa vosotros como pronombre de plural (ustedes estáis, ustedes se/os sentáis) y en la oriental los pronombres se usan de la misma manera que en el resto de las hablas peninsulares (Cano, 2001: 46). 
humor, son perezosos, pero que su habla es incorrecta y la pronunciación mala (Petrović, 2014: 4, 57). Las dos variedades son las hablas del sur y son muy reconocibles. Ambas variedades se califican como inferiores porque carecen de prestigio social, llevando consigo los juicios lingüísticos negativos, escasa valoración sociocultural y estigma para sus hablantes.

Los hablantes tienen diferentes actitudes en cuanto a las variedades estándar/no-estándar, que pueden ser positivas, negativas o neutrales. Tanto las actitudes positivas, como las negativas prueban la presencia de estereotipos. Un cierto número de hablantes tiene la opinión neutral o indiferente acerca de las variedades mayoritariamente estigmatizadas, conscientes de que existen diferentes modalidades de una lengua que difieren entre sí en mayor o menor medida y que este hecho se debe aceptar.

Ciertas respuestas de los encuestados indican un nivel bastante elevado de actitudes negativas hacia las hablas del sur: sólo 11 de 79 examinados (13,92\%) están totalmente de acuerdo de que el programa de los medios locales debería emitirse en las modalidades lingüísticas locales; 12 examinados $(15,19 \%)$ opinan que los estudiantes de la Facultad de Filología deberían comunicar únicamente en la lengua estándar. Los estereotipos Los ciudadanos de Niš bablan graciosamente y El lenguaje de los andaluces es divertido y cómico, están calificados con un valor medio bastante alto 2,74 vs. 2,98 y 3,29, vs. 3,41 (el $1^{\circ}$ vs. el $2^{\circ}$ grupo). Por otro lado, los siguientes juicios están estimados como poco afirmativos: Los andaluces bablan peor español que los madrileños y Las variedades no estándar son babladas por personas con un menor nivel de educación estando valorados con 2,31 vs. 2,17 y 1,87 , vs. 1,95 respectivamente. Según esto se puede concluir que los estudiantes, a pesar de tener plena conciencia de la supuesta igualdad de las variedades lingüísticas, difícilmente superan los fuertes prejuicios y convencimientos tradicionales contra los hablantes de las modalidades meridionales. De esta manera, otra vez se ha confirmado el hecho de que la educación formal lingüística no es decisiva en la creación de los juicios estereotípicos sobre la lengua no estándar.

Las respuestas sugerentes están obtenidas al siguiente concepto: Los bablantes de las variedades del sur de Serbia se estigmatizan en Belgrado. El $1^{\circ}$ grupo valoró la idea con 3,05 y el $2^{\circ}$ grupo con aún $3,9^{6}$. Por una parte, la mayor afirmación

6 Las considerables discrepancias entre las repuestas de dos grupos se han observado solamente en tres preguntas: la mencionada arriba, Los programa de medios locales deberian emitirse en las modalidades lingüisticas locales $(2,74$ vs. 3,22$)$ y Las bablas meridionales serbias son inferiores porque no conocen todos los casos (2,16 vs. 2,54 ). Otras respuestas no han variado a la medida significativa, menos de 0,25 de la calificación media. 
del $2^{\circ}$ grupo se puede explicar con la propia experiencia negativa de los entrevistados en la comunicación con los habitantes de la capital debido a más contactos con ellos. Por otra parte, es probable que durante la educación formal lingüística se tome conciencia de que las variedades no estándar muy a menudo son despreciadas y sus hablantes son estigmatizados.

Los hablantes eligen la variedad que usan, la inferior o la superior. La elección suele depender del registro de habla: en las situaciones comunicativas formales muchas veces se utiliza la variedad estándar en vez de la despreciada. Las posibles razones son la (in)seguridad lingüística, la falta de la conciencia lingüística o el complejo de inferioridad.

No obstante, hay muchos casos de situaciones contrarias: unos hablantes prefieren usar la variedad menos prestigiosa en todas las situaciones comunicativas. No es cosa rara que la variante estándar se considere indeseable, y por lo tanto se rechaza y discrimina. Ellos estiman su modo de hablar, creen que es correcto, usándolo con orgullo y sin escrúpulos; tienden a preservarlo y defenderlo contra los estereotipos, sin ninguna gana de sustituirlo con la variedad estándar. Esto se justifica con la aspiración fuerte del hablante a mantener los lazos estrechos con su colectividad sociocultural o la clase social, mostrando solidaridad y unión (Petrović, 2014: 15-16, 58-59). El empleo de una variedad u otra manifiesta no sólo las actitudes del hablante y la defensa de la identidad lingüística, sino también el nivel de aceptación de cierta modalidad en una comunidad social.

La preservación y el amparo de un habla contribuyen a la lealtad y devoción de sus hablantes hacia la variedad que se usa en la comunidad. Si la variedad goza de prestigio en su contorno social (que no es poco común), es más probable que se conserve, sin ser sustituida por la variedad estándar (Petrović, 2014: 64).

\section{La construcción de la identidad lingüística a través de la estandarización de la lengua y la ideología lingüística}

La lengua estándar es una variedad particular de una lengua que tiene un estatus legal y es considerada como la lengua "ejemplar”, “apropiada” y la "más correcta” (Hernández, 2011: 704; Carbonero, 2011: 80). La lengua estándar es la lengua común, la lengua de todos, la lengua escrita, la variedad superpuesta a otras variedades, suprarregional, la que se ve como modelo. De hecho es una construcción social, un lenguaje visto como el símbolo del estado nacional, 
la variedad seleccionada por los planificadores de la lengua (Filipović/Vučo, 2012: 10). Se usa en las instituciones de la educación formal y en los medios de comunicación y se propaga a través de ellos (Milroy, 2013: 40). Los criterios y marcadores suelen estar basados en el habla del "centro" de la norma, que suele ser la capital, y en la mayoría de los casos suponen el rechazo de otros. La lengua estándar representa el "triunfo" de una variedad, es el "modelo ideal" que sirve de referencia para los hablantes y hace que las variedades que difieren del patrón pierdan prestigio social (Villena, 2001: 94, 95). La lengua estándar está al servicio de la construcción y el mantenimiento de la cultura común de la nación, pero igual sirve para marcar la distinción de otras comunidades lingüísticas (Paffey, 2008: 44).

La lengua estándar es nada más que la variedad de una lengua proclamada como la variedad "oficial" de una comunidad social y política. La forma y la estructura de la lengua se definen a base de la intervención de relevantes instituciones oficiales del estado y expertos en la materia (Filipović, 2009: 14). El término estandarización o normalización supone "una serie o conjunto de actuaciones, más o menos sistematizadas, de política lingüística o de planificación, para dar normas, clarificar y explicar rasgos lingüísticos, darles validez social y promover su utilización" (Carbonero, 2011: 73, 74). Las instancias de estandarización representan a un grupo privilegiado que decide cuál es el habla "buena" o "estándar". La noción de lengua estándar inevitablemente se asocia con las prácticas extralingüísticas: las circunstancias socioculturales, políticas, económicas, geográficas e históricas. La estandarización también transmite motivaciones ideológicas y está estrechamente relacionada con la construcción de la nación ya que favorece los objetivos de la integración interna y segregación externa, convirtiendo la lengua en símbolo de la sociedad (Hernández, 2011: 704), como tal, símbolo de la identidad.

Paffey ha tratado el asunto de la estandarización del español y las prácticas de normalización que se efectúan. Expone una nueva perspectiva de la interconexión del lenguaje y la sociedad, en particular sobre el tema del uso del lenguaje en términos de poder. La estandarización es en primer lugar la ideología (Paffey, 2012: 2). Las prestigiosas variedades "estándar" contrapuestas a las variedades "sub-estándar" provocan la discriminación de los hablantes de las modalidades "no estándar". El autor demuestra que los medios de comunicación representan el "vehículo principal" de propagación de ideologías sobre el idioma español y la construcción de la identidad nacional. Es un instrumento con el que se determina y fija la historia y el desarrollo del español estándar y 
español global (Paffey, 2012: 3, 4). Milroy (2013: 37) lo denomina como la ideología de la lengua estándar o la ideología del estándar lingüistico.

El sistema de educación tiene el rol decisivo en la determinación y formación de la conciencia de nación y estado. De esta manera la identidad lingüística se vincula con la identidad nacional. El discurso ideológico dominante está tejido en la cultura lingüística y en la conciencia de los hablantes. En numerosas situaciones de la vida cotidiana (por ejemplo, en las entrevistas de trabajo), el lenguaje se usa como el criterio de éxito o el fracaso en la selección. El habla de una persona muy a menudo se clasifica como "correcta y aceptable" o "incorrecta y no aceptable", y la califica o no de algo (Paffey, 2012: 5). De este modo, las políticas lingüísticas alientan y refuerzan la desigualdad, y la lengua llega a ser una herramienta de exclusión y discriminación.

La lengua estándar no ha de considerarse como ideal o como el único modelo. Unos hablantes de variedades menospreciadas creen que su forma de hablar es autóctona y que es parte sustancial de su identidad sociocultural.

La cuestión de estandarización de las lenguas e ideologías lingüísticas está estrechamente ligada a la cuestión del nacionalismo. Kordić (2010: 196, 197) afirma que el nacionalismo lingüístico es un producto de "ingeniería social". La identidad nacional es un constructo de la doctrina modelado por la élite social y estatal, es decir sus ideologías políticas y lingüísticas. La lengua es el símbolo de la identidad y pertenencia a un grupo o comunidad, y de la distinción de otros; es una seña de identidad muy importante "identifying an individual as part of the nation and identifying one particular nation as different from all others" (Paffey, 2008: 10). Las diferencias en el uso de la lengua marcan la identidad personal y social. El idioma "...is viewed not only as a functional tool but also as an icon of national identity" (Paffey, 2008: 44).

La estandarización del serbio que se ha realizado durante los últimos $25^{\circ}$ años es un excelente ejemplo de la ordenación lingüística "de arriba hacia abajo" (top-down language management), altamente institucionalizada y centralizada (Filipović/Vučo 2012: 9). Según este patrón -que es el modelo de la mayoría de los idiomas estándar europeos- la estandarización de la lengua se crea conforme al modelo nacionalista de normalización, en insistir en una sola variedad estándar. La lengua se considera como uno de los pilares de la identidad y la unidad nacional, como el patrimonio cultural e histórico más importante. Las variedades de Belgrado y Novi Sad han mantenido su reputación social, mientras que la variedad meridional de la ciudad de Niš nunca 
ganó el prestigio de las mencionadas modalidades del norte (Filipović/Vučo 2012: 11, 26).

Este modelo de planificación lingüística tiene una jerarquía bien definida y estrictamente ordenada e institucionalizada, cerrada a un enfoque heterárquico (Filipović/Vučo 2012: 12, 13). Las estructuras planificadoras deberían ser más tolerantes al cambio lingüístico inherente y menos sujeto a las ideologías lingüísticas, dado que está en un proceso de modificación constante, recibiendo interminablemente la nueva información. En cuanto a la normalización, la práctica lingüística y el comportamiento lingüístico pueden dar entrada a la creación de nuevas actitudes hacia el idioma estándar. Las prácticas corrientes de estandarización son insensibles a las prácticas comunicativas, modelos culturales, cambios sociales y sociolingüísticos, y necesidades reales de la comunidad de habla (Filipović/Vučo 2012: 26).

La encuesta revela una sobrevaloración de la variedad estándar bastante grande. La noción La lengua estándar es la única variedad correcta de una lengua fue calificada con 2,74 vs. 2,71, y la Lengua estándar merecidamente goza de mayor prestigio social que las bablas locales con 3,05 vs. 3,02.

No obstante, hubo respuestas harto controvertidas en comparación con las dos anteriores. La noción La posición de las variedades lingüísticas de una lengua debe ser igual está afirmada por la mayoría de los encuestados, con la calificación media de 3,58 vs. 3,66 , del $1^{\circ}$ y $2^{\circ}$ grupo respectivamente.

\section{Conclusiones}

No existen variedades "más correctas", "más adecuadas" o "mejores" de una lengua. Todas las variedades que sirven satisfactoriamente al propósito de interacción social en ciertas colectividades deberían ser apreciadas y valoradas de igual manera. Cualquier sistema lingüístico, completo y estructurado, que tiene hablantes nativos, es apropiado para la comunicación y creación. No existen las variedades superiores a las demás; existen solamente variedades que gozan de menor prestigio social. Las lenguas son una materia viva que evoluciona y cambia constantemente y, por lo tanto, viven en sus variedades. Si ciertas variedades se consideran inferiores, se trata de una indiferencia general, negligencia de la realidad o, simplemente, de desconocimiento.

Sin embargo, los resultados adquiridos mediante la encuesta -aunque parciales- revelan actitudes bastante conservadoras de los estudiantes de filología hispánica. Desde luego, sería conveniente compararlas con las de los estudiantes de 
otras carreras para obtener una imagen más amplia de la opinión de la población joven universitaria, que se va a incorporar a las futuras investigaciones.

La variedad andaluza del español y las hablas meridionales del serbio llevan consigo un alto estigma social por motivos extralingüísticos diferentes: las ideologías lingüísticas, los estereotipos y prejuicios, los factores históricos y económicos, la falta de conciencia y la ignorancia. Recientemente, con las investigaciones científicas y el cambio de actitudes políticas, ahora más abiertos a las diversidades, las modalidades estigmatizadas empiezan a disfrutar de un estatus igual que sin duda ninguna las pertenece. Con el fomento de tolerancia lingüística y con la promoción de la sensibilidad cultural hacia las diferencias, tanto sociales, étnicas y nacionales, como lingüísticas, la valoración social y el prestigio cultural de las variedades estigmatizadas crece día a día. Igualmente crece la autoestima de los hablantes de las variedades desacreditadas y se consolida y fortalece su identidad lingüística y social.

La necesidad humana de identificarse con un grupo o grupos y verse diferente a otros crea las identidades múltiples y diferenciadas, tanto personales, como colectivas. La rivalidad y el antagonismo lingüístico generan la identidad propia, y pueden debilitarla o reforzarla. La identidad lingüística se construye en parte a través de las ideologías lingüísticas que se imponen por las autoridades. Las instituciones que se ocupan de la estandarización prescriben las normas lingüísticas y las actitudes sobre la lengua y su empleo. Por lo general, propagan los intereses y las aspiraciones nacionales, defendiendo la identidad nacional a través de la lengua. Con la implementación de la ideología de la lengua estándar, las instituciones pretenden imponer una variedad lingüística sobre otras con el fin de afianzar, justificar y objetivar el nacionalismo lingüístico, prestando poca o ninguna atención al mantenimiento de la diversidad lingüística que es de esencial importancia.

\section{Bibliografía}

Amorós Negre, C. (2014): Las lenguas en la sociedad. Madrid: Editorial Síntesis. Belić, Aleksandar (1999): Dijalekti istočne i južne Srbije. Beograd: Zavod za udžbenike i nastavna sredstva.

Bugarski, R. (2010): Jezik i identitet. Beograd: Biblioteka XX vek.

Bustos Tovar, J. J. de (2001): «Lo común y lo diverso en el andaluz». En Carmen Lucía Reina Reina (coord.), Actas de las Jornadas "El babla andaluza: bistoria, normas, usos”. Estepa: Ayuntamiento de Estepa, 255-276. 
Cano Aguilar, R. (2001): «La historia del andaluz». En Carmen Lucía Reina Reina (coord.): Actas de las Jornadas sobre "El habla andaluza: bistoria, normas, usos". Estepa: Ayuntamiento de Estepa, 33-57.

Carbonero Cano, P. (2011): «Sobre la normalización lingüística en Andalucía: antecedentes y perspectivas». En Yolanda Congosto Martín, Elena Méndez García (eds.): Variación lingüística y contacto en el mundo bispánico. Madrid/Frankfurt: Iberoamericana/Veruvert, 73-87.

Filipović, J. (2009): Moć reči. Ogledi iz kritičke sociolingvistike. Beograd: Zadužbina Andrejević.

Filipović, J., J. Vučo (2012): «Language policy and planning in Serbia: language management and language leadership». Anali Filološkog fakulteta, 24 (II): $9-32$.

Hernández Campos, J. M. (2011): «Variation and Identity in Spain». En Manuel Díaz Campos (dir.): The Handbook of Hispanic Sociolinguistics. Malden, MA y Oxford: Wiley-Blackwell, 704-727.

Ivić, P. (2001): Dijalektologija srpskobrvatskog jezika. Uvod u štokavsko narečje. Sremski Karlovci, Novi Sad: Izdavačka knjižarnica Zorana Stojanovića.

Ivić, P. (2009): Srpski dijalekti i njibova klasifikacija. Sremski Karlovci, Novi Sad: Izdavačka knjižarnica Zorana Stojanovića.

Jaspal, R., I. Sitaridou (2013): «Coping with Stigmatized Linguistic Identities: Identity and Ethnolinguistic Vitality among Andalusians». Identity: An International Journal of Theory and Research, 13: 2, 95-119.

Kordić, S. (2010): Jezik i nacionalizam. Zagreb: Durieux.

Milroy, James (2013): «Ideologija standardnog jezika»: Jat, No.1, Zagreb: Filozofski fakultet, $36-43$.

Morillo-Velarde P. R. (2001): «Recorrido lingüístico por la geografía andaluza». En Carmen Lucía Reina Reina (coord.): Actas de las Jornadas sobre "El babla andaluza: bistoria, normas, usos". Estepa: Ayuntamiento de Estepa, 59-88.

Moya Corral, J. A., L. I. Baliña García, A. M. Cobos Navarro (2007): «La nueva africada española». En Juan Antonio Moya Coral, Marcin Sosinski (eds.): Las hablas andaluzas y la enseñanza de la lengua. Granada: Estudios de español actual, 276-284.

Narbona Jiménez, A. (2001): «Norma(s) y hablas andaluzas». En Carmen Lucía Reina Reina (coord.): Actas de las Jornadas sobre "El babla andaluza: bistoria, normas, usos”. Estepa: Ayuntamiento de Estepa, 17-31. 
Narbona Jiménez, A. (2009a): «Prólogo». En Antonio Narbona Jiménez (ed.) et al: La identidad lingüistica de Andalucía, Sevilla: Centro de estudios andaluces, $15-19$.

Narbona Jiménez, A. (2009b): «La identidad lingüística de Andalucía». En Antonio Narbona Jiménez (ed.) et al: La identidad lingüística de Andalucía, Sevilla: Centro de estudios andaluces, 23-63.

Paffey, D. J. (2008): Language, Discourse or Ideology: the Real Academia Española and the Standardization of Spanish. PhD Thesis, University of Southampton.

Paffey, D. J. (2012): Language Ideologies and the Globalization of 'Standard' Spanish. London: Bloomsbury.

Petrović, M. (2014): Jezički stereotipi o španskim i srpskim govorima juga, Tesina de Fin de Máster. FILUM: Universidad de Kragujevac (no publicado).

Tabouret-Keller, A. (1997): «Language and Identity». En F. Coulmas (ed.): The bandbook of sociolinguistics. Oxford: Blackwell, 315-326.

Toma, P. (1998): «Govori Niša i okolnih sela»: Srpski dijalektološki zbornik XLV. Beograd: Srpska akademija nauka i umetnosti, Institut za srpski jezik.

Villena Ponsoda, J. A. (2006): «Andaluz oriental y andaluz occidental: estandarización y planificación en ¿una o dos comunidades de habla?». En Ana $M^{a}$ Cestero Mancera et al: Estudios sociolingüísticos del español de España y América. Madrid: Arco Libros, 233-254.

Vučina Simović, I., J. Filipović (2009): Etnički identitet i zamena jezika u sefardskoj zajednici u Beogradu. Beograd: Zavod za udžbenike. 
Izabela Beljić

University of Belgrade

\section{The construction of linguistic identities: the case of Andalusian variety of Spanish and southern varieties of Serbian}

Key words: linguistic identity, Andalusian variety of Spanish, southern varieties of Serbian, linguistic prestige, stigmatization.

Acceptance, discrimination and stigmatization issues of less socially accepted varieties of language are analysed from the perspective of critical sociolinguistics. The paper discusses the question of linguistic identity in relation to the Andalusian variety of Spanish and southern varieties of Serbian speakers. The comparison of similar linguistic features in Spanish and Serbian serves as a tool to investigate and address the issue of linguistic identity of speakers of both languages. In this way we can observe the interaction between society, language and cultural models, such as language ideologies and the relationship between language and social power. In a survey made among Hispanic Philology students, their views on matters of approval or disapproval of the southern varieties of Serbian and Spanish were verified. The aim is to clarify various beliefs, prejudices, negative attitudes, stereotypes and linguistic judgments that traditionally accompany the two stigmatized varieties. 
Izabela Beljić

Univerza v Beogradu

\section{Gradnja jezikovnih identitet: primera andaluzijske španščine in različic srbščine na južnih govornih območjih}

Ključne besede: jezikovna identiteta, andaluzijska španščina, južne različice srbščine, jezikovni prestiž, stigmatizacija

Prispevek s kritičnega sociolingvističnega vidika obravnava vprašanja sprejemanja, zapostavljanja in stigmatizacije govorcev družbeno manj sprejetih socialnih jezikovnih zvrsti. Posveča se pojavu jezikovnih identitet andaluzijske španščine ter zvrsti južnih govornih področij srbščine. Primerjava sorodnih pojavnosti $v$ španščini in srbščini predstavlja orodje za raziskavo in soočenje $z$ vprašanjem jezikovne identitete govorcev obeh jezikovnih zvrsti. S tem namenom prispevek razčleni sovplivanje med družbo, jezikom in kulturnimi modeli, kot so jezikovne ideologije, ter odnos med jezikom in družbeno močjo. Namen prispevka je pojasniti različna prepričanja, predsodke, odklonilnost, privzete vzorce in jezikovne sodbe, ki običajno spremljajo obe stigmatizirani in podcenjeni zvrsti. 